\title{
Políticas linguísticas e migrações massivas: o caso dos mexicanos nos Estados Unidos e dos turcos na Alemanha
}

Socorro Cláudia Tavares de Sousa ${ }^{a}$ Emny Nicole Batista de Sousa ${ }^{b}$

\begin{abstract}
Resumo
O presente artigo tem como objetivo discutir as politicas linguísticas relacionadas aos processos de migração dos mexicanos nos EUA e dos turcos na Alemanha. Para a realização deste trabalho, adotamos a noção multidimensional de politica linguística de Spolsky $(2004,2009,2013)$ que a compreende a partir das crenças e ideologias, das práticas e da gestão. Essas dimensões são ilustradas a partir de exemplos provenientes de diferentes dominios sociais, como instituições educacionais, organizações governamentais e não governamentais, dentre outros, que, por sua vez, evidenciam o papel da proficiência linguística no processo de integração dos imigrantes na sociedade acolhedora.
\end{abstract}

Palavras-chave: politica linguística, EUA, mexicanos, Alemanha, turcos.

aProfessora Adjunta do Departamento de Letras Clássicas e Vernáculas da Universidade Federal da Paraíba. E-mail: sclaudiats@gmail.com

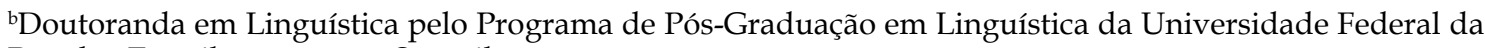
Paraíba. E-mail: emnysousa@gmail.com 


\section{Considerações iniciais}

As migrações massivas são um fenômeno constante na história da humanidade. Como ilustração, desde a década de 1970, temos notícia de um grande fluxo de imigrantes que se desloca do México para os Estados Unidos e, em 2015, de que a Alemanha atingiu um número recorde de um milhão de migrantes ${ }^{1}$. Os governantes desses países têm se posicionado quanto a esses fatos: no caso dos Estados Unidos, o recém-eleito presidente, Donald Trump, defende a ideia de construir um muro nas fronteiras com o México; no caso da Alemanha, a chanceler Angela Merkel, conhecida por sua política de abrir as portas para refugiados islâmicos, declarou que vai agilizar a deportação de tunisianos que tiveram seus vistos negados, após atentado terrorista no Mercado de Natal em Berlim realizado por um tunisiano em dezembro de 2016. Esses e outros eventos geram na opinião pública posicionamentos que variam desde o acolhimento ao migrante a reações contrárias, bem como trazem à tona a discussão sobre o papel das línguas nesse processo, como fator de integração ou de exclusão na sociedade acolhedora, que, por sua vez, pode influenciar as políticas linguísticas para esses grupos.

No campo acadêmico, o interesse pela temática das migrações também tem se constituído tema de diferentes pesquisas, dentre as quais citamos o trabalho de Edwards (2016) que, sob a ótica de uma abordagem crítica da Política Linguística investiga o impacto dos discursos sobre migração nas políticas linguísticas no país de Gales; a de Báez (2013) que analisa a política linguística de falantes de San Lucas que falam uma língua zapoteca (Otomanguean) do vale do estado do sul de Oaxaca no México, na diáspora em Los Angeles na Califórnia. O estudo aborda as ideologias linguísticas presentes nas escolhas das línguas realizadas no domínio familiar e o processo de mudança da língua entre as crianças; o de Orman (2012) que examina as consequências do processo de migração de africanos para a África do Sul depois do apartheid, enfocando os problemas enfrentados por imigrantes relacionados à língua

${ }^{1}$ Informação disponível em: < http://exame. abril.com.br/mundo/ alemanha-busca-ajudaturca-para-reduzirfluxo-de-migrantes/> Acesso em: 26 dez. 2016 e se a intervenção planejada na língua poderia solucionar ou aliviar as tensões vivenciadas por esse grupo.

Dando continuidade a esse veio de pesquisas, o presente artigo tem como objetivo discutir as políticas linguísticas 
relacionadas aos processos de migração dos mexicanos nos EUA e dos turcos na Alemanha. Para a realização deste trabalho, adotamos a noção de política linguística de Spolsky $(2004,2009,2013)$ que a compreende a partir de três dimensões: as práticas, as crenças e a gestão. Essas dimensões foram posteriormente denominadas por Bonacina-Pugh (2013) de políticas linguísticas praticadas (como no caso do ensino da língua local por meio de instituições representadas pela sociedade civil, como as Organizações Não Governamentais), de políticas linguísticas percebidas (as crenças e ideologias acerca da(s) língua(s), tanto por parte do então grupo minoritário quanto por parte da comunidade na qual o grupo está inserido) e de políticas linguísticas declaradas (por meio, por exemplo, do estabelecimento de alguma lei ou discursos que protejam as línguas maternas ou que garantam o ensino da língua local aos imigrantes por quem tenha autoridade de modificar as crenças e as práticas de outrem).

Para fins de organização retórica, afora esta introdução e as considerações finais, o presente artigo está dividido em duas partes: na seção a seguir, discutimos a imigração mexicana nos EUA e na outra, a imigração turca na Alemanha.

\section{Imigração Mexicana nos Estados Unidos}

Os EUA são o país que mais recebe imigrantes no mundo, sejam refugiados, estudantes, trabalhadores, indivíduos ou grupos à procura de melhores condições financeiras, sejam regulares ou não. A nacionalidade que representa o maior número de imigrantes no país é a mexicana. De acordo com o censo feito em 2010 no país, 53\% dos imigrantes nos Estados Unidos são latinos, sendo mais da metade, 55\%, composta por mexicanos (GRIECO et al, 2012). Esse, como todos os movimentos migratórios, tem características próprias e embora tenha se intensificado durante o período do pós-guerra, foi antecedido por momentos de migrações anteriores.

Com a anexação de grande parte do território do país, muitos dos mexicanos que essas terras habitavam, correspondentes aproximadamente aos territórios da Califórnia, de Utah, do Texas e do Novo México, decidiram por ali continuar e, com o tempo, ganhar cidadania estadunidense (GUTIÉRREZ, 2012). Nesse mesmo período, foi iniciada 
a Corrida do Ouro, que atraiu milhares de imigrantes e propulsionou a entrada de mais mexicanos no país. Desde então, os EUA, através dos Atos dos Imigrantes (Immigrant Acts - documentos referentes à naturalização de estrangeiros, concessões de vistos, direitos e deveres dos imigrantes e do Estado, desde o século XIII), tanto proibiu quanto recebeu, de acordo com as necessidades e interesses que iam surgindo. A Revolução do México também produziu emigrantes que se direcionaram ao norte e, mais tarde, durante a Primeira Guerra Mundial, os EUA precisaram novamente de trabalhadores imigrantes e de maneira mais acentuada, na Segunda Guerra. O Congressional Research Service dos EUA divide a imigração mexicana em quatro fases: i) alguns fluxos limitados e sazonais anteriores à Segunda Guerra, ii) durante o Programa Bracero, que acordou contratos temporários (1942-1964), iii) no surgimento de um sistema de imigração ilegal, até os anos oitenta, iv) e com a consolidação desse sistema nos anos noventa em diante, com imigração baseada na instituição familiar (BRICK; ROSEMBLUN, 2011).

Com tantos anos de processos de imigração e contato intercultural, o grupo minoritário ganhou muitos espaços, representação refletida na grande e inegável influência que a língua espanhola e a cultura mexicana exercem no país, desde nomes de cidades como Los Angeles eSan Francisco, e a comida, que mantém os nomes dos pratos em espanhol (muito embora a comunidade local os pronuncie com os sons da língua inglesa) até festas tradicionais do México, como o Día de los Muertos e Cinco de Mayo, sendo esta última uma tradição ainda mais forte nos EUA, pois se celebra também o orgulho e a herança cultural mexicana no país. Afora esses fatores, algumas instituições de ensino superior, como as universidades de Berkeley, Harvard e Stanford oferecem programas de espanhol ou de estudos latino-americanos, bem como há muitas escolas de educação básica que são bilíngues. A educação bilíngue floresceu no pico do movimento dos direitos civis, no fim dos anos 60, no entanto, no início da década de 80 , cresceu o movimento que se opôs à essa educação, culminando, no início dos anos 90, na aprovação de Proposições que restringiram a educação bilíngue em alguns Estados como Califórnia, Arizona e Massachusetts (ARIAS, WILEY, 2013). 
O Peralta Community College District, que abrange quatro faculdades na Área da Baía de São Francisco, é uma das instituições de ensino que possui um programa bem estruturado de cursos em língua espanhola, e vai além, porque também oferece cursos de intérpretes (inglês-espanhol) na área da Medicina e do Direito, Spanish Medical Interpreter e Legal and Community Interpreting Program, respectivamente. No site da instituição, a profissão de intérprete nas cortes é apresentada como uma das mais lucrativas, principalmente devido ao aumento da população falante de espanhol. Outro aspecto que é ressaltado é o fato de que nos campos da saúde e jurídico é fundamental que as informações sejam amplamente compreendidas por médicos/enfermeiros e pacientes, juízes, advogados, réus, enfim, por todas as partes envolvidas. No Estado da Califórnia, por exemplo, entre os anos de 2010 e 2020 é estimado um aumento de $29,2 \%$ de vagas de empregos ${ }^{2}$. O que se observa, portanto, é que a imigração de mexicanos tem proporcionado oportunidades de trabalho para pessoas bilíngues em inglês e espanhol. A nosso ver, entendemos que esses cursos são necessários uma vez que a antiga forma de inserção desses imigrantes, através das traduções feitas pelas gerações mais jovens da família, não é suficiente para suprir as necessidades de interpretação e tradução, acrescentando, ainda, o fato de essa ser uma carreira séria e que garante inserção no mercado de trabalho e um bom retorno financeiro. Nessa perspectiva, os hospitais que já possuíam pessoas que ajudavam na comunicação entre médicos e pacientes agora abriram espaço para a contratação de intérpretes profissionais, que traduzem os sintomas e facilitam o trabalho dos médicos e enfermeiros, de maneira mais adequada, uma vez que foram expostos à nomenclatura utilizada pela Medicina.

Há ainda uma variedade de programas direcionados ao ensino de inglês como segunda língua/língua estrangeira. No Texas, há um programa iniciado pela Baylor University School of Education, chamado de Learning English Among Friends (LEAF), feito para receber os imigrantes e filhos de imigrantes mexicanos no Estado, que correspondem a $63 \%$ da população.

${ }^{2}$ Informação disponível em: < http://www. laney.edu/wp/legalci/ the-interpreter-jobmarket/>. Acesso em: 26 dez. 2016.
Os estudantes são preparados academicamente e os pais recebem aulas de inglês como segunda língua. O programa foi inicialmente dedicado a atender essas famílias, pois a primeira ou segunda geração de imigrantes abandonavam 
a escola de maneira mais frequente. Mais tarde, o programa constatou que os que corriam os maiores riscos de deixar os estudos eram filhos de imigrantes que não liam, escreviam ou falavam inglês, nem entendiam os objetivos e métodos da escola pública. A segunda fase do programa teve o objetivo de engajar as famílias na escola dos filhos, de maneira que eles aprendessem a língua inglesa e se tornassem próximos da educação e cultura americana. O LEAF já contava com mais de 300 alunos adultos nos encontros semanais em 2005 e representa um programa bem-sucedido porque atua em colaboração com três importantes domínios da vida dos imigrantes: a universidade, as escolas públicas e os ambientes de trabalho (WOOD, 2009).

Em San Rafael, na área da Baía de São Francisco, também existe um trabalho que envolve o ensino do inglês como segunda língua aos imigrantes, realizado pela sociedade civil. A ONG chamada Canal Alliance tem a missão de ajudar os imigrantes hispano-falantes da região a obterem sucesso no trabalho e na educação escolar, por meio de fornecimento de alimentos, aconselhamento psicológico, auxílio legal a preços acessíveis e aulas de informática, cidadania e inglês. Assim, em uma região onde se conseguiria viver de forma monolíngue, muitos imigrantes mexicanos e falantes de espanhol "escolhem" falar inglês. No período em que uma das autoras deste artigo ministrou aula nessa ONG, em 2011, como voluntária e para cumprir parte do estágio do Certificado em Ensino de Inglês como Segunda Língua, da Universidade da Califórnia, Berkeley (UC Berkeley Teaching English as a Second Language), foi possível conhecer e observar de perto como se dava essa prática. Parte dos professores dessa organização são voluntários e cada turma tem duas aulas por semana, com duração de duas horas e possui um professor e um ajudante, que é também um professor que está em fase de treinamento. O responsável pela Canal Alliance, Martin Steinman, faz as entrevistas para selecionar os profissionais e um de seus interesses nos candidatos é o domínio da língua espanhola, pois acredita que um professor bilíngue pode intervir com traduções (inglês-espanhol) em momentos necessários. O material didático, composto pelo livro do professor e do aluno, é produzido pela própria ONG, que mantém sua impressão em preto e branco, para a redução de custos. Tendo como 
pressuposto que o livro didático guia o método utilizado em sala de aula, a ONG opta pela abordagem situacional de ensino de língua estrangeira, partindo de situações reais do uso da língua, como comprar frutas, pegar um táxi ou utilizar equipamentos para jardinagem, uma vez que a profissão de "jardineiro" é bastante comum entre a comunidade. O fato é que, mesmo cansados da provável pesada carga horária de trabalho, mesmo tendo que contribuir com um valor, irrisório que seja, para assistir às aulas, as salas de aula da ONG estão lotadas de imigrantes que enxergam, na língua inglesa, possibilidades não de sobrevivência, mas de ascensão social.

Outro domínio em que se pensou necessária a tradução para outras línguas foi o Departament of Motor Vehicles (DMV) da Califórnia (correspondente ao Departamento de Trânsito (DETRAN) do Brasil), o qual disponibiliza provas em diferentes línguas, ou seja, é possível fazer o exame escrito, uma das etapas principais para que se obtenha a carteira de motorista, na língua em que o candidato se sinta mais confortável (as línguas são as correspondentes aos imigrantes na área, sendo a maioria falante de espanhol). E, ainda, na variedade de canais de TV em língua espanhola tanto produzidos no México quanto no próprio país. Exemplos são os canais Telemundo, Univision e MundoFox em espanhol e o canal LATV, bilíngue (espanhol/inglês).

À vista disso, podemos dizer que os esforços realizados pelo Estado e as políticas linguísticas praticadas, advindas da sociedade civil, em relação ao direito dos imigrantes mexicanos de acesso às atividades cotidianas por meio de sua língua materna, são notáveis, em comparação a outros países. Na Califórnia e em outros Estados como o Texas, Flórida e Nova Iorque, o espaço da língua é tão grande e garantido (de maneira evidente ou implícita) que é possível conceber pessoas que moram, vivem e são participantes sociais, no país, sem que se faça necessário o aprendizado da língua inglesa, ou seja, não é preciso falar inglês para tarefas diárias, como ir ao mercado, trabalhar, ir ao médico, assistir TV e, até mesmo, ter habilitação para dirigir ou participar de um júri. A questão é que, embora exista acesso a meios essenciais de sobrevivência nos Estados Unidos, através da língua espanhola, determinadas posições sociais só são "garantidas" por meio da língua inglesa, como a possibilidade de salários maiores e educação superior. 
Afora isso, há também outros aspectos que podem contribuir com a subordinação da língua espanhola à língua inglesa, pelos próprios imigrantes mexicanos. Há uma variedade de pesquisas acerca do preconceito que existe no país, em relação às minorias, aos afro-americanos, e aos imigrantes, especialmente os mexicanos (ESPINO; FRANZ, 2002; SANCHEZ-BURKS, NISBETT, YBARRA, 2000). O preconceito direcionado a esses grupos está correlacionado também à forma como essa minoria é retratada na mídia, referidos como "estrangeiros ilegais", "ilegais", termos que têm uma conotação mais relacionada à invasão de estrangeiros ou a criminosos, e "imigrantes mexicanos" e "trabalhadores sem documentação" (PEARSON, 2010). Motivado por fatores ligados ao preconceito ou não, há, adicionalmente, um movimento político chamado Official English que propaga, desde os anos oitenta, a prática do English Only, que seria o discurso de que nos EUA falar-se-ia somente o inglês, nos domínios públicos e políticos, para que a nação fosse unificada pela língua, refletindo a ideologia linguística de "uma língua, uma nação", além de criticar diretamente os espaços concedidos pelo Estado para outras línguas, principalmente o espanhol, enxergando na língua uma ameaça para a hegemonia da língua inglesa (LAWTON, 2008). De acordo com os políticos e ativistas do movimento, deveria haver uma oficialização da língua inglesa no país. A comunidade que utiliza a língua minoritária não assiste ao movimento de forma passiva e reage de variadas maneiras. Um episódio a esse respeito, que pode ser citado como exemplo, ocorreu quando um grupo de residentes irregulares, em Los Angeles, cantou o hino nacional estadunidense em espanhol, causando desconforto até do então presidente Bush, que declarou, mediante o ocorrido, que o hino nacional só poderia ser cantado em inglês (ARNOUX, 2011).

Por meio dessas ilustrações, é possível perceber como as relações entre políticas linguísticas declaradas, praticadas e percebidas são interdependentes. A língua inglesa nunca foi estabelecida como língua oficial dos EUA, no entanto, intermedeia os acessos à ascensão econômica, além de ser apontada como imperialista em nível global, pela sua associação ao poder, à modernidade, ao mundo tecnológico e ao sucesso profissional. Assim, ao mesmo tempo em que existe a necessidade da manutenção da língua espanhola 
como alicerce da cultura e identidade mexicana no país, há também programas que visam a ajudar a comunidade, por meio do ensino de inglês como segunda língua, acreditando na possibilidade de crescimento profissional e econômico dos migrantes. Da mesma maneira, existem, concomitantemente, ativistas que defendem a preservação das línguas dos imigrantes e que as veem como ameaçadoras da supremacia linguística do inglês no país, mesmo em face do empenho demonstrado por um número significativo de membros das comunidades de imigrantes, no tocante ao aprendizado da língua inglesa, e em face de políticas linguísticas praticadas de não valorização da língua materna/de herança, no domínio da família (BAÉZ, 2013).

Destarte, com mais de um século de imigração e com o fator de pertencimento territorial peculiar ao caso, os mexicanos difundem sua cultura no país e ganham espaços linguísticos em domínios afora aqueles familiares. Contudo, essa minoria continua em situação de inferioridade econômica, recebendo salário bastante abaixo do salário dos locais, ou até mesmo de outros imigrantes que falam a língua inglesa (como é o caso dos canadenses) e continua sendo alvo de preconceito, inclusive pela mídia, quando a eles se refere por meio de termos considerados distanciadores. Nessa perspectiva, a proficiência da língua inglesa pode se constituir em um fator que contribua para o difícil processo de integração na sociedade americana.

\section{Imigração turca na Alemanha}

Outro grupo que também se destaca nas estatísticas de imigração é o grupo minoritário turco no Estado alemão. Depois da Segunda Guerra Mundial, os países começaram a restaurar suas economias e muitos deles experimentaram o chamado "milagre econômico". A Alemanha Ocidental da década de 1960 estava à procura de mão de obra, para dar impulso à sua indústria, encontrando em estrangeiros, alianças. O país fez acordo de recrutamento com países como Espanha, Itália, Portugal, Marrocos, Iugoslávia e Turquia. Este último país foi responsável pelo maior envio de trabalhadores, nos anos sessenta. No início dos anos setenta os turcos já representavam a maioria de estrangeiros no país, seguidos por iugoslavos (PFAFF, 2012). Então, este foi um acordo sustentado 
pelos interesses de ambas as partes. O acordo foi pensado para ser temporário, os turcos trabalhariam na Alemanha durante cerca de cinco anos e depois voltariam à Turquia. Passado o tempo previsto, outros acordos foram sendo estabelecidos, com o apoio das empresas alemãs, e os turcos foram permanecendo. Muitos deles começaram a receber suas famílias da Turquia e outros constituindo novas famílias no país. O resultado é que a maioria desses imigrantes, que foi em caráter temporário, acabou por fixar moradia e permanecer com sua família no país até os dias atuais, já com gerações de turcos nascidos na Alemanha. Miera (2008) afirma que os turcos formam maioria entre os imigrantes no país.

No começo do processo de imigração, provavelmente não houve uma política linguística por parte do governo que garantisse o ensino de alemão para que os turcos pudessem trabalhar, pois não havia essa necessidade, uma vez que o trabalho que eles desempenharam no país, no período do "milagre econômico", era mecânico, e a fluência ou não na língua alemã não interferiria no desempenho no serviço. Outro fator que deve ter contribuído para não ter havido nenhum procedimento em relação a uma política linguística declarada ou mesmo praticada no aprendizado da língua local foi o fato de o contrato de emprego e, portanto, a permanência no país, terem sido temporários, além ainda de os turcos terem se deslocado em grande número, para morar e trabalhar juntos, o que facilitou a comunicação em turco na comunidade, entre os amigos e no ambiente de trabalho. A primeira geração de imigrantes turcos, chamada de Gastarbeiter, portanto, é constituída por grande parte de falantes em um nível muito básico da língua alemã, pois chegaram adultos no país, não tiveram aulas da língua, nem frequentaram a escola, diferentemente da segunda e terceira gerações, que puderam se integrar de maneira mais efetiva à sociedade, a despeito de, muitas vezes, só terem acesso à língua do país acolhedor quando frequentavam a escola no período correspondente à educação básica, em geral, instruídos por professores locais monolíngues em língua alemã (PFAFF, 2012).

Dessa forma, de maneira evidente, os imigrantes ou descendentes tendem a ter menos oportunidades de integração e possibilidades de disputar vagas no mercado de trabalho com os locais. A pesquisa feita pelo Instituto de Berlim para 
População e Desenvolvimento, em 2009, concluiu que dentre os imigrantes com diferentes locais de origem, os turcos apresentaram o menor índice de integração local (ERSANILLI; KOOPMANS, 2009). Provavelmente, por conta disso, o primeiro ministro da Turquia, Recep Tayyip Erdogan, tenha sugerido a abertura de escolas turcas na Alemanha ${ }^{3}$. Há escolas britânicas, americanas e francesas no país, mas as escolas turcas levantaram debate e opiniões controversas, mediante vários fatores, um deles podendo ser atribuído à "estranheza" à cultura oriental.

No livro intitulado Orientalismo, de 1978, o autor Edward Said explicita as raízes que apoiam esse comportamento de estranhamento em relação à cultura oriental, que é nutrido já há muito tempo. Para o autor, as percepções acerca do Oriente são fruto de pressupostos culturais criados pela cultura ocidental, que são preconceituosos e falsos, e, tendo sido sustentados por autoridades da região, foram propagados e tidos como verdades que perduram até os dias atuais, desde a época da expansão colonialista no Oriente. $\mathrm{O}$ autor também afirma que o "próprio orientalismo foi um produto de certas forças e atividades políticas" (SAID, 1978, p. 209) e que essa "doutrina política" foi fundamentada nas línguas europeias, através de expressões idiomáticas, como segue:

As expressões idiomáticas para o Oriente tornaram-se frequentes, e essas expressões assentaram-se firmemente no discurso europeu. Por baixo das expressões idiomáticas havia uma camada de doutrina sobre o Oriente, formadas a partir de experiências de muitos europeus, todas convergindo para aspectos essenciais do Oriente, como o caráter oriental, o despotismo oriental, a sensualidade oriental e coisas do gênero (SAID, 1978, p. 210).

Portanto, esse "sistema de verdades" sobre os orientais pode ter alimentado e justificado um comportamento discriminatório em relação à cultura oriental, causando processos segregacionistas. Há outros fatores que tanto podem

${ }^{3}$ Informação disponível em: <http://www. d w. c o m / p t - b r / o pini $\%$ C $3 \%$ A 3 oa le m a n h a t torna$\mathrm{s}$ e - c a m p o - d e disputas-internasturcas/a-3120994> Acesso em: 26 dez. 2016. dificultar a integração dos turcos na cultura alemã quanto desestabilizar a cultura acolhedora e impedir que haja essa abertura a um tipo de integração que permita a convivência entre diferentes. Em 2010, Thilo Sarrazin, então membro do Partido Social Democrata da Alemanha e senador pelo Estado de Berlim no período de 2002 a 2009, publicou o livro "A 
Alemanha extingue a si mesma" a respeito do problema que o país vem enfrentando no tocante ao fracassado processo de integração dos imigrantes, em especial os de cultura oriental/ turca. O best-seller gerou grande polêmica, uma vez que a temática abordada foi considerada de teor racista e xenofóbico, apontando os custos de uma sociedade multicultural. $\mathrm{O}$ exsenador defende uma política mais restritiva em relação aos imigrantes, além de uma significativa redução dos benefícios destinados aos estrangeiros. $\mathrm{O}$ político alega que, para que haja integração, o esforço deve vir de quem quer se integrar e que a grande maioria desses orientais que vive na Alemanha não merece respeito, pois vive dependendo dos recursos do governo e não se importa em prover educação às suas crianças, que acabarão se tornando tão dependentes quanto os pais. À vista disso, e relacionando a cultura turca à cultura oriental e à religião muçulmana (constituindo uma representação social dessa cultura), o autor considera que a população de muçulmanos tende a aumentar e, portanto, a população alemã, como um todo, tende a ficar cada vez mais crítica quanto à dependência desses imigrantes dos benefícios estatais.

Esse pensamento em relação aos imigrantes é compartilhado por muitos locais, mas também é evitado e debatido por outros. Em um dos discursos do então presidente da Alemanha, Christian Wulff (2010-2012), ele tenta desconstruir essa concepção conscientizando a população da importância da cultura oriental (turca) e da imigração para a construção da Alemanha de hoje, do interesse dos próprios alemães em ter aberto as portas aos imigrantes no contexto do pós-guerra, da contribuição para a diversidade cultural do país e chama atenção para o perigo de um comportamento xenofóbico em relação a estes que são parte da realidade alemã. Também pontua as dificuldades dos Gastarbeiter em aprender a língua alemã naquele primeiro momento, mas ressalta a coragem com a qual as outras gerações se integraram através da educação. $\mathrm{O}$ ex-presidente acentua o papel importante que essas gerações têm hoje, exercendo diferentes profissões importantes no cenário nacional. Muito embora defenda os imigrantes e os trate como iguais perante a lei, em seu discurso, além de valorizar a diversidade cultural por eles trazida para o país, ele associa a integração ao aprendizado da língua local e, mais adiante, ele esclarece a relação entre a aquisição da 
4 "Bildung ist der $\mathrm{Schlüs} \mathrm{s}$ e l für sozialen Aufstieg. Das Beherrschen d e r d e u t s c h e n Sprache ist dafür die Grundvoraussetzung. [...] Eine Studie mit dem Titel "deutschtürkische Lebenswelten 2012" bestätigt, dass [...] 84 Prozent der Befragten klar, dass nur die Beherrschung der deutschen Sprache zum Erfolg führen kann.

Hier sind auch bereits Schritte in die richtige Richtung unternommen worden. Sprachtests lange vor Eintritt in die Schule, verpflichtende Sprachkurse, gezielte Förderung schon in den Kindergärten. Wobei der Wert der Beherrschung e i n e r $\quad \mathrm{z} w$ e i t e n Muttersprache nicht unterschätzt werden darf." (Informação disponível em: < http:// www.kas.de/upload/ Publikationen/2014/ neue_impulse_fuer die_integrationspolitik/ $\begin{array}{llllll}1 & 4 & 0 & 2 & 1 & 2\end{array}$ integrationspolitik wulff.pdf $>$. Acesso em: 17 mai. 2014). língua alemã ao sucesso no processo de integração, citando uma pesquisa feita com os imigrantes turcos, respaldando-se na comunidade minoritária, como segue:

A educação é a chave para o avanço social. O domínio da língua alemã é um pré-requisito básico [...]. Um estudo intitulado "Mundos alemão-turco 2012" confirmou que [...] $84 \%$ dos entrevistados turcos disseram que apenas o domínio do alemão pode levar ao sucesso. Aqui, passos na direção certa já foram dados. São obrigatórios testes de língua antes dos alunos entrarem na escola, cursos de língua, financiamento específico já no jardim de infância, nos quais não devem ser subestimados o valor do controle de uma segunda língua materna ${ }^{4}$. (Grifos nossos)

Nesse excerto de seu discurso, é clara a relação que ele estabelece entre o sucesso da integração dos turcos à Alemanha ao aprendizado da língua local, mas não como língua estrangeira ou língua segunda, e sim como língua materna, mesmo que os imigrantes só venham a ter contato com o alemão quando entram no jardim de infância, com aproximadamente cinco anos de idade. Nesse sentido, a ideia de língua materna, para a maior autoridade política no país à época, representando os ideais do Estado, não está associada ao que se entende na Linguística por língua materna, mas a uma relação afetiva que os imigrantes devem ter com a língua alemã, a fim de que eles possam funcionar no sistema social de fato, contribuindo social e economicamente.

Dr. Ulrich Raiser, da Network Migration in Europe, compartilha da mesma ideia a respeito da língua, em entrevista a respeito das referidas escolas turcas no país. Conquanto ele demonstre entender o Primeiro Ministro da Turquia ter sugerido tais escolas bilíngues, admitindo que esse passo seja importante para a comunidade, ele também deixa clara a primazia da língua local, como no trecho abaixo:

Eu acho que deveria ser claro, desde o início, que o alemão é chave para a integração na Alemanha, e eu não acho que Erdogan se oporia a isso. Quem quiser ser bem-sucedido na sociedade alemã tem de ser capaz de falar alemão - e [...] este é um problema essencial para muitas pessoas turcas que vivem na Alemanha. Às vezes, os pais têm um domínio pobre do alemão ou domínio algum. As crianças, então, têm dificuldades em aprender o alemão dentro de suas famílias, de modo que a primeira vez que realmente aprendem alemão é no jardim de infância ou escola. Por esse tempo, é 
5 "I think it should be clear from the outset that German is key to integration in Germany, and I don't think Erdogan would object to that. Anyone who wants to be successful in German society needs to be able to speak German - and [...] this is an essential problem for many Turkish people living in Germany. Sometimes parents have a poor command of German or know hardly any German at all. Children then have difficulties learning German within their families, so the first time they really learn German is in kindergarten or school. By that time it is really difficult to learn the language properly. This can only be solved by children going to kindergarten and learning German at an early age. If you look at the successful examples of Turkish immigrants in Germany nearly all of them have attended kindergarten at an early age and then gone to school with a fairly good command of German". (Informação disponível em: <http://www. dw.com/en/turkishschools-in-germanywould-show-respectfor-culture/a-5392628>. Acesso em: 20 mai. 2014) realmente difícil aprender a língua de forma adequada. Isso só pode ser resolvido por crianças indo ao jardim de infância e aprendendo alemão em uma idade precoce. Se você olhar para os exemplos bem-sucedidos de imigrantes turcos na Alemanha, quase todos eles participaram do jardim de infância em uma idade precoce e, em seguida, foram à escola com um bom domínio do alemão ${ }^{5}$. (Grifos nossos)

Dessa forma, diferentemente daquele momento em que a Alemanha recebeu milhares de imigrantes e refugiados, existe hoje um programa bastante estruturado, voltado para o ensino de alemão aos imigrantes no país. É uma ação por parte do governo federal, regulamentada em lei, destinada a oferecer diferentes tipos de cursos no intuito de tornar os estrangeiros proficientes em língua alemã. $O$ "curso de integração" consiste em um curso de proficiência em língua alemã e em um curso por meio do qual eles obtêm conhecimento sobre o sistema legal, a história e a cultura da Alemanha. Ele tem duração de seiscentas horas, podendo estender-se para novecentas ou até mil e duzentas horas, dependendo das necessidades adicionais que possam surgir (MULLER, 2005). O objetivo do curso é a aquisição de "competências linguísticas" de acordo com o Quadro Europeu Comum de Referências para as Línguas (QECRL). O curso é considerado bem-sucedido quando o aluno passa num teste de língua e no "curso de orientação", destinado ao ensino do sistema político alemão.

Dessa forma, o Estado alemão, muito embora se apresente como aberto e consciente da diversidade linguística presente no país, tem como política declarada o monolinguismo, uma vez que considera que a integração dos imigrantes só seja efetiva quando estes são proficientes em língua alemã, podendo assim ter acesso à história, à cultura e ao sistema político do país. Essa concepção é anterior à chegada dos imigrantes no contexto do pós-guerra e perdura até os dias atuais, de maneira até mais intensa, mediante os atuais debates e o intensivo programa de ensino de alemão como segunda língua (ou, de acordo com Wulff, como língua materna), proposto e executado somente mais recentemente.

Outro fator importante é a visão do mundo oriental no imaginário coletivo alemão, que contribui para o olhar desconfiado dos locais em direção aos turcos. Esse pensamento, juntamente aos ideais de "multiplicidade linguística conquanto 
${ }^{6}$ Informação disponível em: < http://www. d w . c o m / p t - b r / gera $\% \mathrm{C} 3 \% \mathrm{~A} 7 \% \mathrm{C} 3 \% \mathrm{~A} 3 \mathrm{o}-$ $\mathrm{d}$ e $-\mathrm{t} u$ r c o s alem $\%$ C3\% A3es-lutapara-acabar-comestere\%C3\%B3tipos/ a-2553327>. Acesso em: 27 dez. 2016. que se fale o alemão", atinge diretamente as percepções a respeito da língua por parte desses falantes, que acabam se sentindo inferiorizados frente à comunidade local. Não tendo acesso a melhores empregos, muitos dependem (às vezes unicamente) dos benefícios do governo, fato que também pode nutrir na população local a concepção de que os imigrantes são preguiçosos, ou menos inteligentes.

Logo, há ideologias, representações sociais, mitos e crenças em jogo e em conflito que estabelecem relações de poder e formam diferentes políticas linguísticas percebidas. Essas políticas dependem dos diferentes discursos que são feitos e estão integrados aos valores da comunidade: o sentimento de inferioridade está ligado ao discurso de uma cultura monolíngue e aos preconceitos relacionados à cultura oriental; a resistência em permanecer falando e ensinando aos descendentes e a vontade de que haja certa institucionalização da língua turca está ligada ao direito linguístico de falar a língua materna, que carrega valores culturais, em outros ambientes além do familiar; e esse direito linguístico é sustentado pelo ideal de expansão da cultura oriental, por autoridades turcas. Estes são exemplos de elementos que podem ser adicionados à complexidade que envolve as políticas linguísticas percebidas em relação ao uso de diferentes línguas. Estão diretamente relacionados às políticas linguísticas declaradas e praticadas, como o "curso de integração", que pode estar ligado à experimentada dependência do Estado de um grupo minoritário que não se integra à comunidade local, devido à falta do domínio do alemão, e às escolhas por parte do grupo no tocante ao uso, ou não, tanto da língua turca quanto da língua local, associadas à relação afetiva com a língua dos descendentes ou à ascensão econômica mais facilmente alcançada por meio da língua alemã.

Como o objetivo de acabar com os estereótipos ligados à criminalidade e violência um grupo de jovens turcos-alemães criou uma associação para difundir comerciais de televisão que brincam com esses estereótipos. Esses jovens destacam que "não falar alemão ou falar incorretamente é um dos maiores problemas dos imigrantes turcos e seus descendentes" ${ }^{\prime \prime}$. Por outro lado, o mais recente atentado no Mercado de Natal em Berlim, em dezembro de 2016, fomenta a resistência frente aos 
imigrantes ao mesmo tempo que reforça as críticas à chanceler Angela Merkel por suas políticas migratórias (em 2015, foi permitida a entrada de 890.000 pessoas em busca de asilo). ${ }^{7}$

\section{Considerações finais}

Cada caso descrito neste artigo reflete diferentes aspectos entre migrações e políticas linguísticas, dentre os quais destacamos: i) a relação entre o possível sentimento de pertencimento à terra e aceitação da sociedade acolhedora e o domínio da língua majoritária; ii) a pressão social para o uso da língua majoritária no domínio público, promovendo algumas vezes no domínio privado uma mudança linguística nas gerações mais novas de imigrantes; iii) o direito linguístico de aprender a língua do Outro e ao mesmo tempo manter a língua de herança; iv) tanto nos EUA quanto na Alemanha a presença de discursos nacionalistas que podem afetar as políticas linguísticas.

Observamos que as políticas linguísticas percebidas são assaz significativas e podem estar refletidas nas escolhas da comunidade, como a pesquisa citada por Wulff, que aponta um grande número de imigrantes turcos hoje que associa o domínio da língua alemã ao sucesso e o exemplo da política linguística no domínio da família de ascendência mexicana nos EUA. No entanto, essas políticas, que partem da comunidade, em geral, não criam seus significados do nada, mas se criam, se reformulam e se ressignificam a partir de uma relação de interdependência entre as políticas linguísticas praticadas e as declaradas do Estado. Na verdade, elas são importantes porque são interligadas, considerando que as percepções do

${ }^{7}$ Informação disponível em:<http://brasil.elpais. com/brasil/2016/12/20/ i n t e r n a c i o n a l/ 1482227248410157 html>. Acesso em: 27 dez. 2016.

8 "Las ideologias linguísticas dependem de las ideologias más amplias, que dependem de posições políticas e sujo peso relativo deriva do caráter dominante ou subordinado de las fuerzas em pugna." (ARNOUX; DEL VALLE, 2010 p.3). "mais forte" podem acabar exercendo maior influência nas do grupo minoritário, como bem destacam Arnoux e Del Valle (2010, p. 03) - "As ideologias linguísticas dependem das ideologias mais amplas, que dependem de posições políticas e cujo peso relativo deriva do caráter dominante ou subordinado das forças em conflito"s.

Com a atual conjuntura política europeia e americana, vemos emergir um sentimento de unificação, por meio da língua majoritária, que nos remete ao pensamento de "uma língua, uma nação", como se uma homogeneização da sociedade a fortalecesse de alguma forma, ou prevenisse 
problemas de cunho social e econômico, uma vez que os imigrantes que não falam a língua local muitas vezes acabam dependendo de benefícios do governo, como nos casos expostos. Uma relação de dependência econômica mais forte do que a de interdependência abre caminhos para que o grupo que tem mais poder imponha suas ideologias, por meio das suas decisões sobre a língua ao grupo minoritário, mais fraco. Com esse ideal, em vez de dar suporte linguístico a esses grupos para que, através do bilinguismo, eles possam ter mais independência econômica e acesso aos diferentes domínios dos quais queiram fazer parte, as políticas em relação às línguas podem caminhar numa direção mais restritiva, como com o refreamento do ensino bilíngue (como é o caso do Estado do Arizona, conforme está descrito em Arias e Wiley, 2013), retrocedendo nas questões de direito linguístico e negando as diferentes identidades culturais, por meio de uma política linguística declarada de caráter monolíngue.

\section{REFERÊNCIAS}

ARIAS, M. B.; WILEY, T. G. Language policy and teacher preparation: The implications of a restrictive language policy on teacher preparation. Applied Linguistics Review. v. 4, n. 1, p. 83 -104, 2013.

ARNOUX, E. N. Desde Iguazú: mirada glotopolítica sobre la integración regional. In: Linguas, políticas e ensino na integração regional. Cascavel: ASSOESTE, 2011. p. 38-64.

ARNOUX, E. N.; DEL VALLE, J. Las representaciones ideológicas del lenguaje: discurso glotopolítico y panhispanismo. Spanish in context, v. 7, n. 1, p. 1-24, 2010.

BAÉZ, G. P. Family language policy, transnationalism, and the diaspora community of San Lucas Quiaviní of Oaxaca, Mexico. Language policy. v. 12, n. 1, p. 27-45, 2013.

BONACINA-PUGH, F. Researching 'praticed language policies': insights from conversation analysis. LanguagePolicy. p. 213-234, 2012.

BRICK, K. A. E.; ROSEMBLUN, M. R. Mexican and Central American Immigrants in the United States. Washington, DC: Migration Policy Institute, 2011. 
EDWARDS, C. W. Language policy, in-migration and discursive debates in Wales. Language Policy, v.16, n.2, p.165-188, maio 2017. Publicado online em 4 de março de 2016. doi:10.1007/s10993016-9402-6.

ERSANILLI, E.; KOOPMANS, R. Ethnic Retention and Host Culture Adoption Among Turkish Immigrants in Germany, France and the Netherlands: A Controlled Comparison. WZB, Berlin, 2009.

ESPINO, R.; FRANZ, M. M. Latino Phenotypic Discrimination Revisited: The Impacto f Skin Color on Occupational Status. Social Science Quarterly. v. 83, n. 2, p. 612-623, 2002.

GRIECO, E. M. et al. The Foreign-Born Population in the United States: 2010: American Community Survey Reports. US CENSUS BUREAU. US Departament of Commerce: Economics and Statistics Administration, 2012.

GUTIÉRREZ, D. G. A Historic Overview of Latino Immigration and Demographic Transformation of the United States. American Latinos and the Making of the United States: a Theme Study. Disponível em: < http://www.nps.gov/latino/ latinothemestudy/pdfs/Immigration_web_final.pdf $>$. Acesso em: 13 mar. 2014.

LAWTON, Rachele. Language Policy and Ideology in the United States: A critical analysis of the "English-only" discourse. Lancaster University Postgraduate Conference in Linguistics \& Language Teaching, v.2, p.78-103, 2008.

MIERA, F. Immigration to Germany. Faculty of Cultural Studies, European University Viadrina, Frankfurt/Oder, Germany, 2008. Disponível em: <http://www.migrationeducation. org/22.0.html>. Acesso em: 12 abr. 2014.

MULLER, S. Welcome to Germany Information for Immigrants: Integration Course. Federal Office for Migration and Refugees, Berlin, 2005.

ORMAN, J. Language and 'new' African migration to South Africa: an overview and some reflections on theoretical implications for policy and planning. Language Policy. Springer. v. 11, n. 4, p. 301-322, 2012.

PEARSON, M. R. How "undocumented workers" and "illegal aliens" affect prejudice toward Mexican immigrants. Social Infulence, v. 5, n. 2, p. 118-132, 2010. 
PFAFF, C. Ideologies, Policies and Practices of Multilingualism: Perspectives from Germany. 2012. Disponível em: $<$ https://www. youtube.com/watch?v=we81DeqTLcM>. Acesso em: 05 abr. 2014. SAID, E. Orientalism. Penguin, London, 1978.

SANCHEZ-BURKS, J.; NISBETT, R. E.; YBARRA, O. Cultural Styles, relational Schemas, and prejudice against Out-Groups. Journal of Personality and Social Psychology. v. 79, n. 2, p. 174189, 2000.

SPOLSKY, B. Language policy: key topics in Sociolinguistics. Cambridge: Cambridge, 2004.

Language Management. Cambridge: Cambridge University Press, 2009.

What is language policy? In: The Cambridge Handbook of Language Policy. Cambridge: Cambridge University Press, 2012. p. 03-15.

WOOD, R. M. Teaching ESL to Immigrant Families in Public Schools. Schools in a Pluralistic Culture. p. 66-70, 2009. Disponível em: < http://www.baylor.edu/content/services/document. php/86524.pdf >. Acesso em: 14 jan. 2017. 


\section{Abstract \\ Language policies and massive migrations: the case of Mexicans in the United States and Turks in Germany}

This article aims to discuss the language policies related to the migration processes of Mexicans in the USA and Turks in Germany. To conduct this research, we adopted the multidimensional notion of language policy by Spolsky $(2004,2009,2013)$. who understands it as a set of beliefs, ideologies, practices and, management. We illustrated these dimensions with examples from different social domains, such as educational institutions, governmental and nongovernmental organizations, among others, which in turn highlight the role of linguistic proficiency in the process of integrating immigrants into the host society.

Keywords: language policy, USA, Mexicans, Germany, Turks. 